\title{
Intertwin differences in umbilical artery PI supersede the TTTS Quintero classification in the prediction of infant survival: a retrospective cohort study
}

\author{
Jimmy Espinoza ${ }^{1}$, Michael Belfort (FETAL MEDICINE ISSUE EDITOR) ${ }^{2}$, Alireza \\ Shamshirsaz ${ }^{2}$, Ahmed Nassr², Magdalena Sanz Cortes $^{3}$, Roopali Donepudi ${ }^{1}$, Andres \\ Espinoza $^{1}$, Tiffany Ostovar-Kermani ${ }^{1}$, Rebecca Johnson ${ }^{4}$, Christopher Harman ${ }^{5}$, Halis \\ Ozdemir $^{5}$, and Ozhan Turan ${ }^{5}$ \\ ${ }^{1}$ Baylor College of Medicine and Texas Childrens Hospital Pavilion for Women, Houston, \\ TX, United States \\ ${ }^{2}$ Baylor College of Medicine \\ ${ }^{3}$ BAYLOR COLLEGE OF MEDICINE, TEXAS \\ ${ }^{4} \mathrm{BCM}$ \\ ${ }^{5}$ University of Maryland School of Medicine
}

May 18, 2020

\begin{abstract}
Objective: To evaluate the role of intertwin differences in umbilical artery (UA) pulsatility index (DUAPI) in predicting infant survival in twin-to-twin transfusion syndrome (TTTS) Design: Retrospective cohort study Setting: Baylor College of Medicine, Texas Children's Hospital and University of Maryland School of Medicine Population: Women who underwent laser surgery due to TTTS between 2002 and 2018. Methods: Absolute DUAPI were calculated prior to laser surgery. ROC analysis was done to derive a DUAPI cutoff value of 0.4 for the prediction of double infant survival. Regression analyses were performed to evaluate the association of DUAPI $<0.4$ and infant survival in the whole cohort, in TTTS cases with Quintero stages I/II and in those with Quintero stage III/IV; adjustments for gestational age at delivery, Quintero stage, selective fetal growth restriction (sFGR) and other confounders were done. Main Outcome Measure: Double infant survival to 30 days of life Results: 349 TTTS cases were included. Double twin survival to 30 days was observed in $67 \%(234 / 349)$ of cases. Intertwin DUAPI $<0.4$ was associated with increased double twin survival in the whole cohort (aOR: 3.40; 95\% CI: 2.02-5.70; p<0.001), in women with TTTS Quintero stage I or II (aOR: 3.05; 95\% CI: 1.32-7.09; $\mathrm{p}=0.009$ ) and in women with TTTS Quintero stage III or IV (aOR: $3.23 ; 95 \%$ CI: 1.52-8.85; $\mathrm{p}=0.002$ ). Neither Quintero stage nor sFGR were associated with infant survival. Conclusions: Intertwin differences in UA pulsatility index supersede the Quintero classification in the prediction of double infant survival following laser surgery in TTTS cases.
\end{abstract}

\section{Introduction:}

Twin-to-twin transfusion syndrome (TTTS) is associated with increased risk for fetal or neonatal death in one or both twins as well as with increased risk for long term adverse neurological outcomes. ${ }^{1-6}$ One of the most frequent approaches to evaluate TTTS severity and progression is the Quintero classification system, which is based on sonographic and Doppler findings in the donor and recipient twins. ${ }^{7 ; 8}$ This TTTS staging system is widely used because of its simplicity. However, there are conflicting reports on whether or not the Quintero staging system is predictive of fetal or neonatal survival. ${ }^{7-11}$ Fetal echocardiography has been used to further stratify TTTS severity and to determine the adequate timing for laser photocoagulation of 
placental anastomoses. ${ }^{12-15}$ However, the largest series for the management of TTTS published to date did not include fetal echocardiography information..$^{716 ; 17}$ This is presumably because its role in the evaluation of TTTS severity remains controversial, ${ }^{12-15}$ and because comprehensive fetal echocardiography may not always be available prior to laser surgery.

We previously reported that small intertwin differences in impedance to blood flow in the umbilical arteries (UA) among TTTS cases with Quintero Stage I or II is associated with infant survival independent from gestational age at delivery, Quintero stage, selective fetal growth restriction (sFGR) and other confounding variables. ${ }^{9}$ This study is designed to determine the role of intertwin differences in the UA pulsatility index (DUAPI) in predicting infant survival among TTTS cases with Quintero stages III or IV.

\section{Methods:}

This retrospective cohort study included women with a monochorionic diamniotic twin pregnancy who underwent laser surgery for the management of TTTS, between 2012 and 2018 at Baylor College of Medicine in Houston, Texas and between 2002 and 2017 at the University Of Maryland School Of Medicine in Baltimore, Maryland. Permission was obtained from Institutional Review Boards of both institutions (H-19834, H36458 and HP-00040715-12). Laser surgery was performed when Quintero stage was II to IV, or in Quintero stage I associated with symptomatic polyhydramnios, cervical shortening, or preterm labor.

Laser photocoagulation of placental anastomoses was performed using a single trocar under either local anesthetic with intravenous sedation, regional, or general anesthesia. The trocar was introduced percutaneously using the Seldinger method at one participating institution, whereas direct trocar entry was used at the other institution. The placental vascular anastomoses were identified, and laser was used for photocoagulation under direct fetoscopic visualization. Amnioinfusion (using Ringer's lactate or normal saline solutions) and/or amnioreduction were used at the discretion of the surgeon(s). After laser surgery, most patients returned to their referring institutions to continue with their antenatal care.

Absolute intertwin differences in umbilical artery PI was estimated prior to laser surgery by subtracting the lower pulsatility index (PI) of the UA of either twin from the PI of the UA of the co-twin, as previously reported $^{9}$. TTTS cases were stratified using a DUAPI cutoff value of 0.4 derived from a receiving characteristic curve analysis to evaluate double infant survival to 30 days of life. In order to determine which component of DUAPI is associated with infant survival, separate ROC curve analyses were done for the UA PI of the donor and UA PI of the recipient to predict double survival to 30 days of life in the whole study cohort. Since UA PI changes with gestational age, correlation analyses were done using spearman's rho tests to evaluate the relationship between DUAPI and gestational age at ultrasonography as well as between UA PI of the donor or the recipient twin with gestational age at ultrasonography.

Double infant survival and survival of at least one twin to one month of age was compared between women with a DUAPI [?]0.4 and those with a DUAPI $<0.4$ in the whole cohort and then separately in women with TTTS Quintero stage I or II combined as well as in women with TTTS Quintero stage III or IV combined. The rationale for this is that Quintero stages I and II differ only on the visualization of the fetal bladder of the donor twin; whereas fetal hydrops is the main feature differentiating stage III and IV. Moreover, besides fetal echocardiography, there is currently no other method to further stratify TTTS cases with Quintero stages I or II in order to predict infant survival prior to laser surgery. We previously reported that among TTTS with absent or reversed UA EDF, intermittent UA Doppler abnormalities are associated with higher infant survival when compared to persistent UA Doppler abnormalities ${ }^{9}$.

Stepwise backwards conditional regression analyses were performed to evaluate the association of DUAPI $<0.4$ and double infant survival using a DUAPI of [?]0.4 as a reference, adjusted for gestational age (GA) at surgery, GA at delivery, Quintero stage, selective fetal growth restriction (sFGR) (estimated fetal weight or birthweight discordance [?]25\% and $<10$ th percentile of one twin) ${ }^{18}$, maternal age [?]35 years old, BMI $>35$, placental location (anterior, posterior or lateral with an anterior or posterior component), use of Seldinger method to place the operative trocar, size of the vascular trocar, participating center, use of Solomon technique, laparoscopic-assisted procedure, cerclage and preterm prelabor rupture of membranes (PPROM). 
These regression analyses were done in the whole cohort and then separately in women with TTTS Quintero stage I or II combined as well as in women with TTTS Quintero stage III or IV combined. To evaluate if the sonographic components used in Quintero staging are independently associated with infant survival, a separate regression analysis was performed including the above-mentioned co-variables in addition to the following ones: maximum vertical pocket (MVP) $>8 \mathrm{~cm}$ in the recipient twin, MVP $<2 \mathrm{~cm}$ in the donor twin, absent or reversed UA end diastolic flow (EDF) in either twin, absent or reversed flow during atrial contraction in the ductus venosus of either fetus, and fetal hydrops in either fetus defined as the sonographic finding of two or more of the following: skin edema, ascites, pleural or pericardial effusion. In the regression analyses evaluating the sonographic criteria used in the Quintero classification, Quintero stage was excluded to avoid multicollinearity. Since the MVP cut-off used in the Quintero classification was not derived from an ROC curve analysis ${ }^{7}$ additional regression analyses were done to evaluate the association of the MVP of both donor and recipient twins (as continuous variables) with infant survival adjusting for the above-mentioned confounders.

Comparisons were done using Pearson Chi-square, Fisher Exact, and Mann-Whitney U tests. $\mathrm{P}<0.05$ was considered significant. All statistical analysis was performed using IBM Statistical Package for Social Sciences (SPSS version 24).

\section{Results:}

A total of 418 TTTS consecutive cases underwent laser surgery during the study period at both institutions. UA PI of both donor and recipient twins was available in 89.5\% (374/418) of TTTS cases and DUAPI was calculated in the latter cases. DUAPI was available in $96.4 \%$ (54/56), 99.2\% (132/133), 81\% (158/195), and $88.2 \%(30 / 34)$ of Quintero stage I, II, III and IV cases, respectively. UA PI was recorded in only $65 \%(34 / 52)$ of cases when the UA EDF was absent or reversed in either twin, even though PI could be estimated in these cases. All cases where UA PI was available in both twins were included in the study ( $\mathrm{n}=374) ; 6.7 \%(25 / 374)$ of these cases were lost to follow-up to 30 days of life, leaving 349 cases for analysis. For the analysis, one participating center contributed with 118 cases and the other one with 231 cases. TTTS Quintero stage I or II was diagnosed in 176 cases and TTTS Quintero stage III or IV was diagnosed in 173 cases. In the whole cohort, double twin survival and survival of at least one twin to 30 days was observed in $67 \%(234 / 349)$ and 90.3\% (315/349), respectively. The demographic and clinical characteristics according to Quintero stages and DUAPI results are described in Tables 1 and 2.

ROC curve analysis demonstrated that higher inter-twin DUAPI was associated with reduced dual infant survival to 30 days of life [area under the curve $(\mathrm{AUC})$ : $0.67 ; \mathrm{p}<0.001$ ]. These results are consistent with an earlier report at a single institution ${ }^{9}$. Of note, ROC curve analysis demonstrated that higher UA PI in donor twin, (AUC: $0.66 ; \mathrm{p}<0.001$ ) but not in the recipient twin (AUC: $0.45 ; \mathrm{p}=0.1$ ), was also associated with reduced dual infant survival to 30 days of life. These observations suggest that the association of DUAPI with double infant survival in TTTS cases undergoing laser surgery is primarily driven by UA PI in the donor twin. We chose to use DUAPI instead of UA PI in the donor twin because it does not have a significant correlation with gestational age at ultrasonography (spearman's rho correlation coefficient: $-0.03 ; \mathrm{p}=0.6$ ). As expected, UA PI in the donor twin had a significant correlation with gestational age at ultrasonography (spearman's rho correlation coefficient: $-0.16 ; \mathrm{p}=0.02$ ). Thus, the clinical use of UA PI in the donor twin to predict infant survival in TTTS requires the use of a normogram. In contrast, intertwin DUAPI does not change with gestational age, and the use of a single cutoff $(<0.4)$ is simple to use.

The donor twin had higher UA PI that the recipient twin in 56.7\% (198/349) of TTTS cases and sFGR was identified in $21.5 \%(75 / 349)$ of cases. Of note, in only $66.7 \%(50 / 75)$ of TTTS cases with sFGR, the donor twin had higher UA PI than in the recipient twin; we anticipated this proportion to be higher because of the known association of sFGR with increased impedance to blood flow in the UA.

Significant differences in double twin survival to 30 days of life was seen between DUAPI groups in the whole cohort $[<0.4: 76.8 \%(162 / 211)$ vs. [?]0.4: $52.2 \%(72 / 138) ; \mathrm{p}<0.001]$ and in the subgroup of women with TTTS Quintero stage I or II combined [<0.4: $77.8 \%(105 / 135)$ vs. [?]0.4: $58.5 \%(24 / 41)$; p=0.015] 
as well as in women with TTTS Quintero stage III or IV combined $[<0.4: 75 \%(57 / 76)$ vs. [?]0.4: $49.5 \%$ (48/97); $\mathrm{p}=0.001$ ] (see Table 2). Similar findings were observed when double twin survival to 30 days of life was compared between the two DUAPI groups in TTTS cases with Quintero stage I individually $[<0.4$ : $88.1 \%(37 / 42)$ vs. [?]0.4: $54.5 \%(6 / 11) ; \mathrm{p}=0.02]$ or Quintero stage III individually $[<0.4: 80.3 \%(49 / 61)$ vs. [?]0.4: $50 \%(43 / 86) ; \mathrm{p}<0.001]$. Among women with Quintero stages II or IV as individual groups, those with a DUAPI $<0.4$ had higher double twin survival to 30 days than those with a DUAPI [?]0.4, but these differences did not reach statistical significance in either group \{Quintero stage II $[<0.4: 73.1 \%(68 / 93)$ vs. [?]0.4: $60 \%(18 / 30) ; \mathrm{p}=0.1]$ or Quintero stage IV [<0.4: $53.3 \%(8 / 15)$ vs. [?]0.4: $45.5 \%(5 / 11) ; \mathrm{p}=0.6]\}$.

No significant differences in survival of at least one twin to 30 days of life was seen between DUAPI groups in the whole cohort $[<0.4: 91 \%(192 / 211)$ vs. [?]0.4: $89.1 \%(123 / 138) ; \mathrm{p}=0.6]$ or in the subgroup of women with TTTS Quintero stage I or II combined [<0.4: $91.9 \%(124 / 135)$ vs. [?]0.4: $90.2 \%(37 / 41)$; p=0.7] or in women with TTTS Quintero stage III or IV combined [<0.4: $89.5 \%(68 / 76)$ vs. [?]0.4: $88.7 \%$ (86/97); $\mathrm{p}=0.9]$. In a multivariable regression analysis, DUAPI $<0.4$ was not associated with survival of at least one infant to 30 days [adjusted odds ratio (aOR): $0.64,95 \%$ confidence interval $(\mathrm{CI}): 0.19-2.2 ; \mathrm{p}=0.5$ ] in the whole study cohort or in the subgroup analyses.

Intertwin DUAPI $<0.4$ was associated with a 3 -fold to 3.5 -fold increase in double twin survival to one month of age in the regression model of the whole cohort and the subgroup analysis (See Tables 3,4 and 5). This was determined using DUAPI [?]0.4 as a reference when the analysis was adjusted for confounding variables. Indeed, intertwin DUAPI $<0.4$ was associated with increased survival of both twins to one month of age in the whole cohort (aOR: 3.40; 95\% CI: 2.02-5.70; $\mathrm{p}<0.001$ ) (Table 3), in the subgroup of women with TTTS Quintero stage III or IV (aOR: 3.23; 95\% CI: 1.52-8.85; $\mathrm{p}=0.002$ ) (Table 4) as well as in those with TTTS Quintero stage I or II (aOR: 3.05; 95\% CI: 1.32-7.09; $\mathrm{p}=0.009$ ) (Table 5). As anticipated, an additional variable associated with increased double twin survival to one month of age was gestational age delivery (See Tables 3, 4 and 5). In contrast, neither Quintero staging nor any of the sonographic criteria used in Quintero staging or sFGR were associated with infant survival when the analysis was adjusted for confounding factors (See Tables 3, 4 and 5). Similar findings were observed when the MVP of the donor (aOR: 0.91; 95\% CI: $0.70-1.19 ; \mathrm{p}=0.5$ ) or recipient twin (aOR: $0.98 ; 95 \%$ CI: $0.89-1.10 ; \mathrm{p}=0.8$ ) were included as continuous variables in the regression models.

There were significant differences in the proportion of women with double infant survival to 30 days according to Quintero staging [81.1\% (43/53), 69.9\% (86/123), $62.6(92 / 147)$ and 50\% (13/26) for Quintero stage I, II, III and IV, respectively; $\mathrm{p}=0.002]$. In contrast, no significant differences were observed for survival of at least one twin to 30 days according to Quintero staging [92.5\% (49/53), 91.1\% (112/123), $90.5(133 / 147)$ and $80.8 \%$ (21/26) for Quintero stage I, II, III and IV, respectively; $\mathrm{p}=0.2]$. The observation that Quintero staging was associated with double infant survival in the univariate analysis but not after the analysis was adjusted for DUAPI $<0.4$ and other confounders in the multivariable regression model (Table 3) indicates that DUAPI $<0.4$ supersedes the Quintero classification in the prediction of double infant survival to 30 days of life in TTTS cases.

\section{Discussion:}

\section{Main Findings:}

The results of our study demonstrate that intertwin differences in umbilical artery impedance to blood prior to laser surgery supersede the Quintero classification (or any of its sonographic criteria) in the prediction of double infant survival in TTTS cases. These observations are consistent with an earlier report indicating that intertwin DUAPI $<0.4$ is associated with increased infant survival in TTTS cases where both fetuses have positive end-diastolic flow in the umbilical arteries (Quintero stages I and II) prior to laser surgery ${ }^{9}$. This study further demonstrates that the same applies to TTTS cases with Quintero stages III or IV when the statistical analysis is adjusted for gestational age at delivery, sFGR, and other important confounders.

\section{Strengths and Limitations}


Our study has all the limitations of a retrospective review, and it is possible that a few donor or recipient cases were mislabeled when the databases were generated; however, this should not affect the results of our study since DUAPI represents the absolute intertwin differences in UA PI. In addition, 6.7\% (25/374) of TTTS cases were lost to follow-up to 30 days, but there were no significant differences in the proportion of lost to follow-up cases between the DUAPI groups $(<0.4$ and [?]0.4), which reduces the possibility of selection bias. Similarly, the proportion of double twin survival to 30 days was not different between TTTS cases included or excluded in the study based on DUAPI availability ( $67 \%$ vs. $68.6 \%$; $=0.9$ ), which should also reduce the risk of selection bias. Strengths of the study are the inclusion of consecutive patients at two large academic institutions, and the regression analyses performed, which was adjusted for important confounding variables such as gestational age at delivery, sFGR, placental location, size of the trocar, and Quintero staging among others.

\section{Interpretation}

TTTS complicates only a small proportion of monochorionic diamniotic (MC DA) twin pregnancies even though intertwin placental anastomoses are demonstrated in the vast majority of MC DA twin pregnancies with or without TTTS ${ }^{19-23}$. Thus, the presence of placental anastomoses is necessary but not sufficient for the net transfer of blood from the donor to the recipient twin in TTTS. Unequal distribution of the placental mass may also contribute to the pathogenesis of TTTS since the estimated fetal weight of the donor twin is typically smaller than the recipient twin; however, if we use selective fetal growth restriction as a proxy of unequal placental sharing, sFGR is seen in only a small proportion of TTTS cases as demonstrated by the $21 \%$ prevalence of sFGR in our study. The smaller placental mass allocated to the donor twin should have a smaller placental bed vasculature and higher downstream vascular resistance than the placental mass allocated to the recipient twin. However, this may not always be the case because we observed that impedance to blood flow in the umbilical arteries was higher in the recipient twin than in the donor twin in $43.3 \%$ of the TTTS cases requiring laser surgery. Thus, it is possible that the allocation of the placental bed vasculature responsible for downstream umbilical artery resistance may not necessarily correspond to the allocation of placental mass in all TTTS cases. Our observations that small intertwin differences in UA impedance to blood flow are associated with increased double twin survival to 30 days of life in TTTS cases following laser surgery suggest that intertwin differences in UA PI may provide novel metrics to evaluate the severity and disease progression in $\mathrm{TTTS}^{9}$.

The observation that small intertwin DUAPI $(<0.4)$ supersedes the Quintero classification or any of its sonographic criteria in the prediction of double twin survival when the analysis is adjusted for gestational age at delivery, sFGR and other important confounders is noteworthy. This was observed in the multivariable regression analysis of the whole study cohort, as well as in women with TTTS Quintero stage I or II combined as well as in those with TTTS Quintero stage III or IV combined. This is probably because intertwin DUAPI may better reflect the underlying mechanisms or disease in TTTS compared to the sonographic criteria used in the Quintero classification, which relies on amniotic fluid volume in both twins, significant fetal Doppler anomalies and the presence or absence of fetal hydrops, which tend to normalize following laser surgery. Intertwin differences in UA impedance to blood flow may also improve following laser surgery, but these intertwin differences may better reflect the severity of the disease processes leading into TTTS in view of their association with double infant survival.

Since the Quintero classification is widely used to evaluate TTTS cases, we propose using an intertwin DUAPI of $<0.4$ to further stratify the Quintero staging system in order to evaluate the possibility of double infant survival following laser surgery. In the sub analysis restricted to individual Quintero stages, women with a DUAPI $<0.4$ had higher double infant survival than those with DUAPI [?]0.4. These differences were significant in Quintero stages I and III, but not in Quintero stages II and IV as individual groups. This is likely because our study was underpowered to perform these sub-analyses.

\section{Conclusions}

Collectively, our observations indicate that the estimation of intertwin differences in vascular impedance to 
umbilical artery blood supersedes the Quintero staging in the prediction of double infant survival in TTTS cases. DUAPI $<0.4$ is associated with a three-fold increase in double infant survival to 30 days of life in cases undergoing laser photocoagulation of placental anastomoses for the management of TTTS cases with Quintero stages I and II as well as in those with Quintero stages III and IV. Intertwin differences in the umbilical artery pulsatility index may provide novel metrics to evaluate the progression and severity of TTTS cases requiring laser surgery.

Disclosure of Interests and Contribution to Authorship:

We confirm that all authors including JE, MAB, AAS, AAS, MSC, RD, AFE,TGO, RMJ, CH, HO and OT have met the conditions of authorship.

We confirm that all authors including JE, MAB, AAS, AAS, MSC, RD, AFE,TGO, RMJ, CH, HO and OT declared no conflicts of interests with this manuscript.

Details of ethics approval: The study received approval from the Baylor College of Medicine Institutional Review Board and University Of Maryland School Of Medicine (H-19834, H-36458 and HP-00040715-12).

Funding: Baylor College of Medicine (BCM), internal funding

Reference List

1. Lopriore E, Middeldorp JM, Sueters M, Oepkes D, Vandenbussche FP, Walther FJ. Long-term neurodevelopmental outcome in twin-to-twin transfusion syndrome treated with fetoscopic laser surgery. Am J Obstet Gynecol 2007;196:231-34.

2. Li X, Morokuma S, Fukushima K, Otera Y, Yumoto Y, Tsukimori K et al. Prognosis and long-term neurodevelopmental outcome in conservatively treated twin-to-twin transfusion syndrome. BMC.Pregnancy Childbirth. 2011;11:32.

3. van Klink JM, Koopman HM, Oepkes D, Walther FJ, Lopriore E. Long-term neurodevelopmental outcome in monochorionic twins after fetal therapy. Early Hum.Dev. 2011;87:601-06.

4. Rossi AC, Vanderbilt D, Chmait RH. Neurodevelopmental outcomes after laser therapy for twin-twin transfusion syndrome: a systematic review and meta-analysis. Obstet Gynecol 2011;118:1145-50.

5. van Klink JM, Koopman HM, Rijken M, Middeldorp JM, Oepkes D, Lopriore E. Long-Term Neurodevelopmental Outcome in Survivors of Twin-to-Twin Transfusion Syndrome. Twin.Res.Hum.Genet. 2016;19:25561.

6. Miralles-Gutierrez A, Narbona-Arias I, Gonzalez-Mesa E. Neurological complications after therapy for fetal-fetal transfusion syndrome: a systematic review of the outcomes at 24 months. J Perinat.Med 2018;46:991-97.

7. Chmait RH, Kontopoulos EV, Korst LM, Llanes A, Petisco I, Quintero RA. Stage-based outcomes of 682 consecutive cases of twin-twin transfusion syndrome treated with laser surgery: the USFetus experience. Am J Obstet Gynecol 2011;204:393-96.

8. Quintero RA, Morales WJ, Allen MH, Bornick PW, Johnson PK, Kruger M. Staging of twin-twin transfusion syndrome. J Perinatol. 1999;19:550-55.

9. Espinoza AF, Belfort MA, Shamshirsaz AA, Hudson KM, Parisi X, Nassr AA et al. Impedance to blood flow in the umbilical arteries and infant survival in twin-to-twin transfusion syndrome. Ultrasound Obstet Gynecol 2019.

10. Ville Y. Twin-to-twin transfusion syndrome: time to forget the Quintero staging system? Ultrasound Obstet Gynecol 2007;30:924-27.

11. Duryea EL, Happe SK, McIntire DD, Dashe JS. The natural history of twin-twin transfusion syndrome stratified by Quintero stage. J Matern.Fetal Neonatal Med 2016;29:3411-15. 
12. Van Mieghem T, Klaritsch P, Done E, Gucciardo L, Lewi P, Verhaeghe J et al. Assessment of fetal cardiac function before and after therapy for twin-to-twin transfusion syndrome. Am J Obstet Gynecol 2009;200:400-07.

13. Michelfelder E, Gottliebson W, Border W, Kinsel M, Polzin W, Livingston J et al. Early manifestations and spectrum of recipient twin cardiomyopathy in twin-twin transfusion syndrome: relation to Quintero stage. Ultrasound Obstet Gynecol 2007;30:965-71.

14. Stirnemann JJ, Mougeot M, Proulx F, Nasr B, Essaoui M, Fouron JC et al. Profiling fetal cardiac function in twin-twin transfusion syndrome. Ultrasound Obstet Gynecol 2010;35:19-27.

15. Stirnemann JJ, Nasr B, Proulx F, Essaoui M, Ville Y. Evaluation of the CHOP cardiovascular score as a prognostic predictor of outcome in twin-twin transfusion syndrome after laser coagulation of placental vessels in a prospective cohort. Ultrasound Obstet Gynecol 2010;36:52-57.

16. Diehl W, Diemert A, Grasso D, Sehner S, Wegscheider K, Hecher K. Fetoscopic laser coagulation in 1020 pregnancies with twin-twin transfusion syndrome demonstrates improvement in double-twin survival rate. Ultrasound Obstet Gynecol 2017;50:728-35.

17. Stirnemann J, Djaafri F, Kim A, Mediouni I, Bussieres L, Spaggiari E et al. Preterm premature rupture of membranes is a collateral effect of improvement in perinatal outcomes following fetoscopic coagulation of chorionic vessels for twin-twin transfusion syndrome: a retrospective observational study of 1092 cases. BJOG. 2018;125:1154-62.

18. Khalil A, Rodgers M, Baschat A, Bhide A, Gratacos E, Hecher K et al. ISUOG Practice Guidelines: role of ultrasound in twin pregnancy. Ultrasound Obstet Gynecol 2016;47:247-63.

19. Lopriore E, Slaghekke F, Middeldorp JM, Klumper FJ, van Lith JM, Walther FJ et al. Accurate and simple evaluation of vascular anastomoses in monochorionic placenta using colored dye. J Vis.Exp. $2011 ; \mathrm{e} 3208$.

20. Hack KE, Nikkels PG, Koopman-Esseboom C, Derks JB, Elias SG, van Gemert MJ et al. Placental characteristics of monochorionic diamniotic twin pregnancies in relation to perinatal outcome. Placenta 2008;29:976-81.

21. De Paepe ME, DeKoninck P, Friedman RM. Vascular distribution patterns in monochorionic twin placentas. Placenta 2005;26:471-75.

22. Zhao D, Lipa M, Wielgos M, Cohen D, Middeldorp JM, Oepkes D et al. Comparison Between Monochorionic and Dichorionic Placentas With Special Attention to Vascular Anastomoses and Placental Share. Twin.Res.Hum.Genet. 2016;19:191-96.

23. Zhao DP, de Villiers SF, Slaghekke F, Walther FJ, Middeldorp JM, Oepkes D et al. Prevalence, size, number and localization of vascular anastomoses in monochorionic placentas. Placenta 2013;34:589-93.

Table 1. Demographic and Clinical characteristics of the study population

\begin{tabular}{|c|c|c|c|c|c|c|}
\hline & $\begin{array}{l}\text { Quintero } \\
\text { stage I or } \\
\text { II }\end{array}$ & $\begin{array}{l}\text { Quintero } \\
\text { stage I or } \\
\text { II }\end{array}$ & $\mathbf{p}$ & $\begin{array}{l}\text { Quintero } \\
\text { stage III } \\
\text { or IV }\end{array}$ & $\begin{array}{l}\text { Quintero } \\
\text { stage III } \\
\text { or IV }\end{array}$ & $\mathbf{p}$ \\
\hline & $\begin{array}{l}\text { DUAPI } \\
<0.4 \\
(\mathrm{n}=135)\end{array}$ & $\begin{array}{l}\text { DUAPI } \\
{[?] 0.4} \\
(n=41)\end{array}$ & & $\begin{array}{l}\text { DUAPI } \\
<0.4 \\
(\mathrm{n}=76)\end{array}$ & $\begin{array}{l}\text { DUAPI } \\
{[?] 0.4} \\
(n=97)\end{array}$ & \\
\hline $\begin{array}{l}\text { Maternal age } \\
\text { (years) }\end{array}$ & $30.0(18-45)$ & $33.0(18-46)$ & 0.6 & $29.5(18-47)$ & $32(17-50)$ & 0.3 \\
\hline AMA & $28.1(38 / 135)$ & $36.6(15 / 41)$ & 0.3 & $25.0(16 / 76)$ & $28.9(28 / 97)$ & 0.6 \\
\hline
\end{tabular}




\begin{tabular}{|c|c|c|c|c|c|c|}
\hline & $\begin{array}{l}\text { Quintero } \\
\text { stage I or } \\
\text { II } \\
\end{array}$ & $\begin{array}{l}\text { Quintero } \\
\text { stage I or } \\
\text { II } \\
\end{array}$ & $\mathrm{p}$ & $\begin{array}{l}\text { Quintero } \\
\text { stage III } \\
\text { or IV }\end{array}$ & $\begin{array}{l}\text { Quintero } \\
\text { stage III } \\
\text { or IV }\end{array}$ & $\mathbf{p}$ \\
\hline $\begin{array}{l}\text { Maternal BMI } \\
\left(\mathrm{kg} / \mathrm{m}^{2}\right)\end{array}$ & $\begin{array}{l}27.2 \\
(17.7-60.2)\end{array}$ & $\begin{array}{l}24.7 \\
(11.5-46.1)\end{array}$ & 0.09 & $\begin{array}{l}26.6 \\
(17.4-52.1)\end{array}$ & $\begin{array}{l}25.7 \\
(17.2-53.5)\end{array}$ & 0.6 \\
\hline $\begin{array}{l}\text { Maternal } \\
\text { obesity }\end{array}$ & $11.9(16 / 134)$ & $7.3(3 / 41)$ & 0.5 & $20.0(15 / 75)$ & $11.3(11 / 97)$ & 0.1 \\
\hline $\begin{array}{l}\text { GA at surgery } \\
\text { (weeks) }\end{array}$ & $\begin{array}{l}20.7 \\
(16.1-25.6)\end{array}$ & $19.5(16-26.1)$ & 0.08 & $\begin{array}{l}20.4 \\
(15.1-25.9)\end{array}$ & $20.4(16-29)$ & 0.9 \\
\hline $\begin{array}{l}\text { Trocar size } \\
(\mathrm{mm})\end{array}$ & $3.4(3.0-4.2)$ & $3.4(1.3-4.1)$ & 0.5 & $3.4(1.3-4.2)$ & $3.4(1.1-4.2)$ & 0.2 \\
\hline sFGR & $14.1(19 / 135)$ & $22.0(9 / 41)$ & 0.2 & $18.4(14 / 76)$ & $34.0(33 / 97)$ & 0.02 \\
\hline $\begin{array}{l}\text { Laser-to- } \\
\text { delivery } \\
\text { interval (days) }\end{array}$ & $77.4(0-131.6)$ & $78.4(1-142.1)$ & 0.5 & $\begin{array}{l}75.6 \\
(0.7-154.7)\end{array}$ & $64.1(0-150.5)$ & 0.5 \\
\hline $\begin{array}{l}\text { GA at delivery } \\
\text { (Weeks) }\end{array}$ & $\begin{array}{l}32.3 \\
(18.4-38.3)\end{array}$ & $\begin{array}{l}32.5 \\
(19.6-40.1)\end{array}$ & 0.8 & $\begin{array}{l}32.1 \\
(17.7-40.1)\end{array}$ & $30.2(16.4-41)$ & 0.4 \\
\hline $\begin{array}{l}\text { Cervical } \\
\text { length }(\mathrm{cm})\end{array}$ & $4(1.4-5.4)$ & $3.9(0.9-6.2)$ & 0.7 & $4(0.6-6)$ & $3.6(0.5-6.2)$ & 0.07 \\
\hline Cerclage & $3.7(5 / 135)$ & $4.9(2 / 41)$ & 0.2 & $2.6(2 / 76)$ & $6.3(6 / 96)$ & 0.3 \\
\hline PPROM & $25(32 / 128)$ & $13.9(5 / 36)$ & 0.2 & $20.3(14 / 69)$ & $27.5(25 / 91)$ & 0.2 \\
\hline $\begin{array}{l}\text { Use of } \\
\text { Solomon } \\
\text { technique }\end{array}$ & $89.6(121 / 135)$ & $90.2(37 / 41)$ & 0.9 & $90.8(69 / 76)$ & $89.7(87 / 97)$ & 0.8 \\
\hline $\begin{array}{l}\text { Laparoscopic- } \\
\text { assisted } \\
\text { procedure }\end{array}$ & $6.7(9 / 135)$ & 0 & 0.09 & $3.9(3 / 76)$ & $4.1(4 / 97)$ & 0.9 \\
\hline
\end{tabular}

Variables expressed as median and range or proportion and percentages; body mass index (BMI); advanced maternal age (AMA: > 35 years old); maternal obesity (BMI>35); intertwin differences in umbilical artery pulsatility index (DUAPI); body mass index (BMI); selective fetal growth restriction (sFGR); preterm prelabor rupture of membranes (PPROM).

Table 2. Fetal or infant survival according to Quintero stage and intertwin differences in umbilical artery pulsatility index

\begin{tabular}{|c|c|c|c|c|c|c|}
\hline & $\begin{array}{l}\text { Quintero } \\
\text { stage I or } \\
\text { II }\end{array}$ & $\begin{array}{l}\text { Quintero } \\
\text { stage I or } \\
\text { II }\end{array}$ & $\mathbf{p}$ & $\begin{array}{l}\text { Quintero } \\
\text { stage III } \\
\text { or IV }\end{array}$ & $\begin{array}{l}\text { Quintero } \\
\text { stage III } \\
\text { or IV }\end{array}$ & $\mathbf{p}$ \\
\hline & $\begin{array}{l}\text { DUAPI } \\
<0.4 \\
(\mathrm{n}=135)\end{array}$ & $\begin{array}{l}\text { DUAPI } \\
{[?] 0.4} \\
(n=41)\end{array}$ & & $\begin{array}{l}\text { DUAPI } \\
<0.4 \\
(\mathrm{n}=76)\end{array}$ & $\begin{array}{l}\text { DUAPI } \\
{[?] 0.4} \\
(n=97)\end{array}$ & \\
\hline $\begin{array}{l}\text { Double } \\
\text { survival at } \\
\text { birth (\%) }\end{array}$ & $83.0(112 / 135)$ & $65.9(27 / 41)$ & 0.02 & $84.2(64 / 76)$ & $55.7(54 / 97)$ & $<0.001$ \\
\hline $\begin{array}{l}\text { At least one at } \\
\text { birth }(\%)\end{array}$ & $97.8(132 / 135)$ & $92.7(38 / 41)$ & 0.1 & $93.4(71 / 76)$ & $92.8(90 / 97)$ & 0.9 \\
\hline $\begin{array}{l}\text { Death of at } \\
\text { least one fetus }\end{array}$ & $17.0(23 / 135)$ & $34.1(14 / 41)$ & 0.02 & $15.8(12 / 76)$ & $44.3(43 / 97)$ & $<0.001$ \\
\hline
\end{tabular}

$(\%)$ 


\begin{tabular}{lllllll}
\hline & $\begin{array}{l}\text { Quintero } \\
\text { stage I or } \\
\text { II }\end{array}$ & $\begin{array}{l}\text { Quintero } \\
\text { stage I or } \\
\text { II }\end{array}$ & $\mathbf{p}$ & $\begin{array}{l}\text { Quintero } \\
\text { stage III } \\
\text { or IV }\end{array}$ & $\begin{array}{l}\text { Quintero } \\
\text { stage III } \\
\text { or IV }\end{array}$ & p \\
\hline $\begin{array}{l}\text { Death of both } \\
\text { fetuses (\%) }\end{array}$ & $2.2(3 / 135)$ & $7.3(3 / 41)$ & 0.1 & $6.6(5 / 76)$ & $7.2(7 / 97)$ & 0.9 \\
$\begin{array}{l}\text { Double } \\
\text { survival at } 30 \\
\text { days (\%) }\end{array}$ & $77.8(105 / 135)$ & $58.5(24 / 41)$ & $<0.001$ & $75.0(57 / 76)$ & $49.5(48 / 97)$ & 0.001 \\
$\begin{array}{l}\text { At least one at } \\
30 \text { days (\%) }\end{array}$ & $91.9(124 / 135)$ & $90.2(37 / 41)$ & 0.02 & $89.5(68 / 76)$ & $88.7(86 / 97)$ & 0.9 \\
\hline
\end{tabular}

Variables expressed as proportion and percentages; intertwin differences in umbilical artery pulsatility index (DUAPI).

Table 3. Logistic Regression analysis to evaluate variables determining dual twin survival to 30 days of life in the whole study cohort

\begin{tabular}{|c|c|c|c|c|}
\hline Predictor & Crude Odds & & Adjusted Odds & \\
\hline Variables & Ratio (95\% CI) & $\mathbf{p}$ & Ratio (95\% CI) & $\mathbf{p}$ \\
\hline DUAPI $<0.4^{*}$ & $3.03(1.90-4.81)$ & $<0.001$ & $3.40(2.02-5.70)$ & $<0.001$ \\
\hline Trocar size (mm) & $0.99(0.64-1.55)$ & 0.98 & $1.26(0.69-2.32)$ & 0.44 \\
\hline Anterior placenta & $0.39(0.11-1.48)$ & 0.17 & $0.52(0.13-2.16)$ & 0.38 \\
\hline Cerclage & $0.97(0.33-2.92)$ & 0.96 & $0.69(0.19-2.44)$ & 0.56 \\
\hline Solomonization & $0.80(0.37-1.72)$ & 0.13 & $1.23(0.48-3.17)$ & 0.67 \\
\hline $\begin{array}{l}\text { Laparoscopic } \\
\text { assisted }\end{array}$ & $1.50(0.47-4.76)$ & 0.49 & $0.49(0.12-1.93)$ & 0.31 \\
\hline Maternal obesity & $1.40(0.69-2.83)$ & 0.35 & $0.72(0.32-1.62)$ & 0.42 \\
\hline AMA & $1.29(0.78-2.14)$ & 0.32 & $0.92(0.51-1.66)$ & 0.79 \\
\hline $\begin{array}{l}\text { Participating } \\
\text { center }\end{array}$ & $0.71(0.44-1.15)$ & 0.16 & $1.19(0.63-2.26)$ & 0.59 \\
\hline Preterm PROM & $0.67(0.39-1.13)$ & 0.13 & $1.04(0.55-1.96)$ & 0.90 \\
\hline $\begin{array}{l}\text { GA at surgery } \\
\text { (weeks) }\end{array}$ & $1.12(1.02-1.22)$ & 0.02 & $1.08(0.97-1.19)$ & 0.16 \\
\hline $\begin{array}{l}\text { GA at delivery } \\
\text { (weeks) }\end{array}$ & $1.16(1.10-1.23)$ & $<0.001$ & $1.13(1.06-1.21)$ & $<0.001$ \\
\hline Quintero stage & $0.64(0.49-0.85)$ & 0.002 & $0.89(0.63-1.25)$ & 0.49 \\
\hline sFGR+ & $0.51(0.30-0.85)$ & 0.01 & $1.26(0.68-2.31)$ & 0.46 \\
\hline $\begin{array}{l}\text { Absent/reversed } \\
\text { UA EDF in either } \\
\text { fetus }\end{array}$ & $0.89(0.51-1.59)$ & 0.71 & $0.66(0.31-1.43)$ & 0.29 \\
\hline $\begin{array}{l}\text { Absent/reversed } \\
\text { flow in DV in } \\
\text { either fetus in } \\
\text { atrial kick }\end{array}$ & $0.91(0.42-1.97)$ & 0.81 & $0.73(0.18-3.05)$ & 0.67 \\
\hline $\begin{array}{l}M V P>8 \mathrm{~cm} \\
\text { recipient twin }\end{array}$ & $0.89(0.45-1.74)$ & 0.72 & $1.11(0.50-2.47)$ & 0.79 \\
\hline $\begin{array}{l}\text { MVP }<2 \mathrm{~cm} \\
\text { donor twin }\end{array}$ & $1.02(0.55-1.89)$ & 0.95 & $0.86(0.41-1.81)$ & 0.68 \\
\hline $\begin{array}{l}\text { Hydrops in either } \\
\text { fetus }\end{array}$ & $0.46(0.21-1.03)$ & 0.06 & $2.05(0.75-5.57)$ & 0.16 \\
\hline
\end{tabular}


Adjusted for gestational age (GA) at delivery, GA at ultrasound assessment, Quintero stage, selective fetal growth restriction (sFGR), advanced maternal age (AMA; [?] 35 years), maternal obesity (body mass index $\left.>35 \mathrm{~kg} / \mathrm{m}^{2}\right)$, preterm prelabor rupture of membranes (PPROM); intertwin difference in umbilical artery pulsatility index (DUAPI), umbilical artery (UA) end-diastolic flow (EDF), ductus venosus (DV) flow during atrial contraction and maximum vertical pocket (MVP) in the donor or recipient twin. +Estimated fetal weight $(E F W)$ or birthweight discordance [?] $25 \%$ and EFW $<10^{\text {th }}$ percentile for GA. * DUAPI [?]0.4 was used as reference.

Table 4. Logistic Regression analysis to evaluate variables determining dual twin survival to 30 days of life in TTTS cases with Quintero stage III or IV combined

\begin{tabular}{|c|c|c|c|c|}
\hline Predictor & Crude Odds & & Adjusted Odds & \\
\hline Variables & Ratio $(95 \%$ CI $)$ & $\mathbf{p}$ & Ratio $(95 \%$ CI $)$ & $\mathbf{p}$ \\
\hline$\overline{\text { DUAPI }<0.4^{*}}$ & $3.06(1.59-5.89)$ & 0.001 & $3.23(1.52-8.85)$ & 0.002 \\
\hline Trocar size (mm) & $1.11(0.67-1.87)$ & 0.67 & $1.22(0.56-2.63)$ & 0.61 \\
\hline Anterior placenta & $0.30(0.03-2.70)$ & 0.29 & $0.41(0.03-5.70)$ & 0.50 \\
\hline Cerclage & $0.59(0.18-1.89)$ & 0.37 & $0.34(0.06-2.16)$ & 0.26 \\
\hline Solomonization & $1.10(0.43-2.81)$ & 0.85 & $1.59(0.42-6.04)$ & 0.50 \\
\hline $\begin{array}{l}\text { Laparoscopic } \\
\text { assisted }\end{array}$ & $7.30(0.92-57.71)$ & 0.06 & $0.26(0.03-2.54)$ & 0.25 \\
\hline Maternal obesity & $1.67(0.70-3.99)$ & 0.25 & $0.72(0.32-1.62)$ & 0.42 \\
\hline AMA & $1.21(0.65-2.25)$ & 0.54 & $0.83(0.34-2.02)$ & 0.69 \\
\hline $\begin{array}{l}\text { Participating } \\
\text { center }\end{array}$ & $0.66(0.37-1.18)$ & 0.16 & $1.04(0.38-2.90)$ & 0.94 \\
\hline Preterm PROM & $0.43(0.22-0.83)$ & 0.01 & $1.70(0.71-4.04)$ & 0.23 \\
\hline $\begin{array}{l}\text { GA at surgery } \\
\text { (weeks) }\end{array}$ & $1.06(0.96-1.17)$ & 0.27 & $1.17(1.02-1.33)$ & 0.02 \\
\hline $\begin{array}{l}\text { GA at delivery } \\
\text { (weeks) }\end{array}$ & $1.13(1.05-1.21)$ & 0.001 & $1.11(1.02-1.23)$ & 0.02 \\
\hline Quintero stage & $0.61(0.28-1.35)$ & 0.22 & $0.44(0.15-1.23)$ & 0.13 \\
\hline sFGR+ & $0.51(0.27-0.92)$ & 0.03 & $2.07(0.94-4.64)$ & 0.08 \\
\hline $\begin{array}{l}\text { Absent/reversed } \\
\text { UA EDF in either } \\
\text { fetus }\end{array}$ & $1.42(0.79-2.57)$ & 0.24 & $0.53(0.23-1.20)$ & 0.13 \\
\hline $\begin{array}{l}\text { Absent/reversed } \\
\text { flow in DV in } \\
\text { either fetus in } \\
\text { atrial kick }\end{array}$ & $1.51(0.72-3.15)$ & 0.27 & $0.56(0.11-3.01)$ & 0.50 \\
\hline $\begin{array}{l}M V P>8 \mathrm{~cm} \\
\text { recipient twin }\end{array}$ & $1.0(0.43-2.34)$ & 0.99 & $0.85(0.26-2.76)$ & 0.79 \\
\hline $\begin{array}{l}\text { MVP }<2 \mathrm{~cm} \\
\text { donor twin }\end{array}$ & $0.95(0.43-2.08)$ & 0.89 & $2.01(0.67-6.02)$ & 0.21 \\
\hline $\begin{array}{l}\text { Hydrops in either } \\
\text { fetus }\end{array}$ & $0.59(0.26-1.38)$ & 0.95 & $2.82(0.89-8.89)$ & 0.16 \\
\hline
\end{tabular}

Adjusted for gestational age (GA) at delivery, GA at ultrasound assessment, Quintero stage, selective fetal growth restriction (sFGR), advanced maternal age (AMA; [?] 35 years), maternal obesity (body mass index $>35 \mathrm{~kg} / \mathrm{m}^{2}$ ), intertwin difference in umbilical artery pulsatility index (DUAPI), ), preterm prelabor rupture of membranes (PPROM), umbilical artery (UA) end-diastolic flow (EDF), ductus venosus (DV) flow during atrial contraction and maximum vertical pocket $(M V P)$ in the donor and recipient twin. + Estimated fetal weight $(E F W)$ or birthweight discordance [?] 25\% and EFW $<10^{\text {th }}$ percentile for GA. * DUAPI [?]0.4 was 
used as reference.

\section{Hosted file}

Table 5.docx available at https://authorea.com/users/323264/articles/452048-intertwindifferences-in-umbilical-artery-pi-supersede-the-ttts-quintero-classification-in-theprediction-of-infant-survival-a-retrospective-cohort-study 